Derecho \& Realidad

Núm. 23 • I semestre de 2014

Facultad de Derecho y Ciencias Sociales, UPTC

ISSN: 1692-3936

\title{
Reflexiones sobre la toma, retoma del Palacio de Justicia, y recientes condenas a militares implicados en la retoma
}

\author{
Reflections on taking and retaking of the \\ Courthouse, and recent convictions to military \\ officers involved in the retaking
}

Semillero de investigación Rafael Uribe Uribe

\section{Resumen}

El semillero de investigación Rafael Uribe Uribe es una idea que nace de la ausencia de producción intelectual no convencional en la Facultad de Derecho y Ciencias Sociales de la Uptc, para reivindicar la esencia axiológica de esta, implícita en su nombre «Facultad de Derecho y Ciencias Sociales», mediante la producción de tesis ideales ratificadas en la práctica material de dicho conocimiento. Con tal fin se ha iniciado un proceso de investigación basada en las garantías constitucionales y legales que el Estado otorga para ejercer oposición a partir de la Constitución de 1991, interpretando sus contextos materiales y formales.

Como punto de partida y primer avance de investigación se analizan los hechos sucedidos los días 6 y 7 de noviembre de 1985 en Bogotá durante la toma y retoma del Palacio de Justicia perpetradas por el M-19. Se hace énfasis en las desapariciones de las personas que salieron con vida luego de la retoma por parte del Ejército, y las recientes condenas a los militares implicados en su desaparición, a través del estudio de los fallos condenatorios, 
desde una prospectiva penal, constitucional, de derecho comparado y desde la argumentación jurídica, especialmente con base en los postulados de la escuela del activismo judicial. Se resalta la importancia del papel que asume la rama judicial, que en un Estado y una democracia como la colombiana, en actuaciones como esta, toma un mal llamado estatus de oposición sufriendo una victimización como consecuencia de la realización objetiva de sus funciones.

\section{Palabras clave}

Desaparecidos, insurgencia, victimización, autor mediato, democracia, justicia, legalidad.

\section{Abstract \\ The research seedbed Rafael Uribe Uribe is an idea born of the absence of unconventional intellectual production in Law and Social Sciences School from the UPTC, in order to claim this axiological essence, implicit in its name School of Law and Social Sciences, through ideal thesis upheld in the material practice of such knowledge. To this purpose it has initiated a research process based on the constitutional and legal guarantees that the state gives to exercise opposition from the 1991 Constitution, interpreting its materials and formal contexts.}

As a starting point and first step of research we analyze the facts occurred on 6 and 7 November 1985 in Bogota during the taking and retaking of the Courthouse perpetrated by the M-19, emphasizing the disappearance of the people who survived after the retaking by the Army, and the recent convictions of the soldiers involved in the disappearance, analyzing prospective convictions from a criminal, constitutional, and comparative law from the legal argument especially based on the postulates of the school of judicial activism. We highlights the important role carried out by the judiciary that in a state and a democracy such as the Colombian, in performances like this, takes a socalled opposition status suffering victimization as a result of the objective performance of its duties.

\section{Key words}

Missing, insurgency, victimization, perpetrator, democracy, justice, legality. 
"La doble moral de garantizar la vida y la libertad y por otro lado patrocinar la muerte y el engaño es la típica esencia de los gobernantes colombianos y su legalidad"

Rafael Uribe Uribe.

El 6 de noviembre de 1985, el comando Iván Marino Ospina, adscrito al Movimiento 19 de abril (M-19), en cumplimiento de la operación Antonio Nariño por los derechos del hombre, toma por asalto las instalaciones del Palacio de Justicia en Bogotá, con la finalidad de realizar un juicio político al presidente Belisario Betancourt por su responsabilidad en el fracaso de los diálogos de paz entablados meses atrás entre la insurgencia y el Estado.

El contexto social de la época muestra al M-19 como una guerrilla nacionalista social demócrata, porque «el M-19 luego de Jorge Eliecer Gaitán fue un movimiento político, que ha propuesto cosas propias al país como el socialismo a la colombiana o socialismo autóctono, creando ideologías autónomas a los modelos ya implantados alrededor del mundo, con una existencia axiológica formal dependiente de estas pero con existencia material independiente» (Vargas, 2006).

El M-19 fue creado el 19 de abril de 1970 como reacción popular al fraude electoral mediante el cual Misael Pastrana, candidato del partido conservador, ganó las elecciones presidenciales al general (R) Gustavo Rojas Pinilla, candidato de la ANAPO, dando así continuidad al pacto oligárquico del Frente Nacional, el cual no permitía la llegada al poder a partidos o movimientos políticos diferentes a los dos partidos tradicionales, los cuales pactaron alternarse en el poder durante cuatro periodos presidenciales, dividiendo en partes iguales las cuotas burocráticas de administración del Estado. Su primera acción pública fue la recuperación de la espada de Bolívar el día 17 de enero de 1974, «el robo de las elecciones de 1973 fue la oportunidad perfecta, aprovechada por el Flaco Bateman para iniciar su proyecto revolucionario propio, tomando como centro de partida la gran cantidad de masas aglomeradas en la ANAPO»(Villamizar, 2007).

El M-19 estaba constituido en su base por jóvenes intelectuales, en su mayoría provenientes de las grandes ciudades, que con anterioridad habían pertenecido a las FARC-EP, movimiento insurgente del cual fueron expulsados por disidencias ideológicas, como es el caso de Jaime Bateman Cayón y Álvaro Fayad, o desertaron, como Carlos Pizarro León Gómez e Iván Marino Ospina, entre otros. Ellos coincidían en el carácter urbano que debe tener la lucha armada en Colombia para llevar a cabo la revolución popular, que entregue el poder al pueblo, postulados básicos de la organización político- militar que constituyó el M-19. La característica propia del M-19 fue su innovación, pues se alejaron de los modelos clásicos de 
insurgencia cubana representada en el ELN y la leninista tradicional abanderada por las FARC-EP, pues dieron un toque bolivariano a su esencia, alejándose del socialismo soviético dogmático y proponiendo una democracia real, es decir, un verdadero gobierno de la mayorías sobre las minorías, que se preocupe por el bienestar de sus ciudadanos y que respete las libertades individuales de estos.

El contexto histórico que enmarcaba el continente y el mundo era la vanguardia de la lucha entre el socialismo y el capitalismo (guerra fría), lucha que desencadenaba guerras, revoluciones y contrarrevoluciones, hechos sobre los cuales el continente latinoamericano y Colombia no pasaron desapercibidos, pues el reciente golpe de Estado en Chile al presidente Salvador Allende inició los parámetros a seguir en cuanto a las políticas de seguridad interna que implantaron todos los gobiernos dependientes del poderío norteamericano en el hemisferio sur. Lo que Richard Nixon denominó como «lucha indirecta para evitar la infiltración del comunismo», dicha política de seguridad interna fue implantada en nuestro país por primera vez durante el Gobierno de Julio César Turbay, cuando recibió el nombre de Estatuto de Seguridad Nacional, (muy parecido a la reciente política de seguridad democrática del Gobierno de Álvaro Uribe). Dicha política consistió en dotar con facultades extraordinarias a los militares, como la de juzgar en cortes marciales a los civiles, realizar detenciones y capturas sin previa orden judicial, utilizar métodos bárbaros para la obtención de información, como la tortura; el constreñimiento como medio de mantener la seguridad nacional, es decir, las amenazas, el secuestro y la desaparición dirigida hacia todas las personas que se consideraran peligrosas para la institucionalidad, por sus actos o pensamientos. Esta doctrina fue enseñada por primera vez por los militares norteamericanos a militares chilenos y uruguayos, los cuales la aplicaron a cabalidad, para luego enseñarlo a los militares colombianos, quienes demostraron lo aprendido, generando excelentes resultados. Cabe resaltar que nuestro país vivió en estado de sitio por más de dos décadas.

Durante la década de los 70 y los 80, el M-19 propinó certeros golpes que hicieron tambalear al gobierno y menoscabaron el orgullo de los altos mandos militares, tales como, el robo de armas al Cantón Norte, la toma de la Embajada dominicana, entre otros. En los años 80, el gobierno empezó una serie de acercamientos con la insurgencia, con el fin de buscar salidas negociadas al conflicto, el M-19 no fue ajeno a dicha situación y una de las alternativas planteadas por Bateman antes de su desaparición física en un accidente aéreo, fue la de buscar la paz mediante negociaciones bilaterales,

La paz es justicia social, la paz es educación, salud, vivienda, trabajo, pan para todos los colombianos la paz la única salida a la guerra civil pero dicha paz en ningún momento es arrodillarse y entregar las armas al enemigo, así como así, porque mientras este país este como esta nosotros tenemos que estar ahí, esa es la labor del M-19. (Bateman, 1982) 
Los primeros acercamientos de paz entre el M-19 y el Estado colombiano se dieron durante el Gobierno de Belisario Betancourt en el municipio de Corinto, en el departamento del Cauca. Allí se firmó una tregua de cese al fuego y no realización de acciones militares de parte bilateral, como condición indispensable para los acercamientos que deberían abrir camino a los diálogos, mediante la entrada en vigencia de una mesa de negociación para la materialización de la desmovilización. En vigencia del «cese al fuego bilateral», las Fuerzas Armadas y la Policía del Estado colombiano hicieron parte formal pero no material del acuerdo, pues sus constantes acciones hostiles hacia el M-19 fueron un común denominador, hasta el punto que Carlos Pizarro, comandante de la insurgencia, minutos antes de firmar el acuerdo con el Gobierno, fue atacado por un comando de la Policía, que trató de impedir su llegada al lugar. Además, se presentaron los combates de Yarumales, en donde las tropas oficiales sufrieron un gran revés táctico porque la insurgencia logró romper el cerco «indestructible» que buscaba acabar con el M-19. Este revés tactito para los militares aumentó el tamaño de la herida a su orgullo, causada anteriormente por acciones como el robo de las armas al Cantón Norte, entre otras. Además, la guerra pública ante los medios de comunicación se estaba perdiendo, por lo cual urgía una acción que devolviera temor y respeto al Ejército. Las constantes hostilidades por parte del Ejército a la subversión durante la tregua, el asesinato selectivo de líderes guerrilleros en plena tregua, hizo que la insurgencia rompiera lo diálogos y volviera a la clandestinidad, argumentando su decisión en el constante saboteo de los militares a los intentos de paz. Tras el rompimiento de los diálogos, Álvaro Fayad, como máximo comandante del M-19, planeó una acción pública para aclarar al país la verdad sobre los intentos de paz y sobre quién recaía la responsabilidad política por su fracaso. Dicha operación recibió el nombre de Antonio Nariño, por los derechos del hombre, y fue asignada al comando Iván Marino Ospina (nombre que se dio en honor al líder insurgente asesinado en su casa en Cali por la policía meses antes, durante el marco de la tregua y cese al fuego). Los encargados de liderar dicha acción fueron Andrés Almarales y Luis Otero, también se encontraban personalidades como Alfonso Jacquin e Irma Franco. La secular característica de los militantes del comando Iván Marino Ospina fue que todos eran abogados de profesión, pero trasformadores sociales de vocación.

La toma del Palacio de Justicia fue el día 6 de noviembre de 1985 a las 10 y 30 de la mañana. El primer reducto del M-19 entró por el costado occidental, cinco minutos después ingresó el segundo reducto al Palacio de Justicia, por la entrada principal de la Plaza de Bolívar, y tomó el control sobre el edifico aproximadamente a las 11. Un tercer reducto no logró ingresar al Palacio, debido a que quedó en medio de un retén policial en la carrera $7^{\mathrm{a}}$. Hay que resaltar la poca vigilancia y seguridad presente en el Palacio de Justicia ese día, pues, en la entrada, solo se contaba con dos celadores de una empresa de seguridad privada y dos agentes de policía, razón por la cual durante el inicio de la incursión guerrillera solo hubo dos víctimas fatales. 
La situación en mención fue analizada a profundidad durante los tres fallos jurídicos en contra de los militares por su responsabilidad en la desaparición de las personas que lograron salir con vida del Palacio de Justicia, y se llegó a la conclusión que la fuerza pública conocía con antelación por información de inteligencia los planes de la guerrilla para asaltar la edificación y por razones aún desconocidas para la nación, no se tomaron las medias de seguridad pertinentes, incluso se sabe que un día antes fueron notoriamente reducidas las medidas de seguridad sobre el palacio.

Durante la toma, el comando del M-19 se atrincheró en sitios estratégicos del Palacio, como las escaleras del segundo y tercer piso y el baño oriental del último piso de la edificación. La reacción de la fuerza pública fue extremadamente rápida, pues sobre las 11 y 15 de la mañana ya estaban arribando los primeros tanques de guerra tipo cascabel a la Plaza de Bolívar y los encargados militares de la «operación tricolor», nombre que se dio a la retoma del Palacio de Justicia, empezaban a acomodar la Casa del Florero como centro de información y combate, desde el cual se iba a comandar la operación. Dichos encargados militares fueron el general Jesús Armando Arias Cabrales, comandante de la Brigada XIII, el coronel Alfonso Plazas Vega, comandante de la Escuela de Caballería, unidad adscrita a la Brigada XIII, el coronel Sánchez Rubiano, comandante del B2 o brigada de inteligencia militar en Bogotá, estos últimos como encargados mediatos, pues como encargados inmediatos estaban el presidente de la República, Belisario Betancourt, el ministro de Defensa, general Samudio, y el comandante de las Fuerzas Militares, general Mallarino Vásquez. Todo esto según la línea de mando institucional para la fuerza pública. Los enfrentamientos para recuperar el control del Palacio de Justicia duraron hasta la tarde del 7 de noviembre de 1985, momento en el cual se logró controlar el baño del tercer piso, lugar donde se encontraba el último foco de resistencia guerrillera.

La actividad conciliadora del Gobierno durante la toma fue escasa, pues de nada sirvieron las incesantes súplicas telefónicas del presidente de la Corte Suprema de Justicia, Alfonso Reyes Echandía, quien imploraba al presidente para que diera la orden al Ejército de suspender el fuego. Estas fueron las palabras textuales de Reyes Echandía: «!Que el Ejército cese el fuego por que nos están asesinando!» A esto hay que sumar la censura oficial hacia los medios de comunicación, a los cuales se les prohibió trasmitir imágenes de lo que estaba sucediendo en el Palacio de Justica, censura promovida por la ministra de Comunicaciones Noemí Sanín, quien dio la orden de trasmitir un partido de fútbol. Y ni hablar del fuego desproporcionado, pues los disparos que salían de los tanques contra el Palacio, según la Fiscalía, ocasionaron el incendio a la biblioteca donde se encontraban todos los expedientes de recientes investigaciones contra militares por violaciones de derechos humanos en el marco del conflicto armado, expedientes de los cuales no existía ninguna copia de en otra dependencia judicial. También se encontraban 
cinco expedientes contra narcotraficantes con posibilidad de extradición, de los cuales existía copia en la Embajada americana y en el despacho presidencial, motivo por el cual, de forma objetiva, la Fiscalía ha descartado la posible infiltración del narcotráfico en la financiación de la toma del Palacio por parte del M-19.

La tarde del 7 de noviembre de 1985 arrojó nefastos resultados para la nación, pues cobró la vida de 94 personas, entre militantes del M-19, magistrados, trabajadores y visitantes ocasionales del Palacio de Justica. En esa ocasión perdieron la vida ilustres juristas, lo que hizo que se negara la posibilidad al país de disfrutar de su obra intelectual, como es el caso de Alfonso Reyes Echandía, Carlos Medellín, Alfonso Patiño Roselli y el magistrado auxiliar Manuel Gaona. Además dejó al país sin Corte Suprema de Justicia «la máxima representación de la democracia fue sacrificada en nombre de la democracia por parte del gobierno colombiano» (Petro, 2007, p. 204). Y a esto hay que añadir que 12 personas - entre ellas nueve empleados de la cafetería, la militante del M-19, Irma Franco, la proveedora de pasteles de pollo a la cafetería y una visitante ocasional del Palacio, que se encontraba donde una familiar que laboraba como magistrada auxiliar-, quienes salieron con vida del Palacio de Justica la tarde del 7 de noviembre para ser trasladadas por soldados a la Casa del Florero, lugar en el que se les vio por última vez, y de quienes, hasta la fecha, no se tiene conocimiento sobre su paradero.

Por la desaparición de estas doce personas fueron juzgados y declarados culpables el coronel Plazas Vega y el general Arias Cabrales, siendo penados con 30 años de prisión, en decisiones judiciales que causaron gran polémica porque implantaron en el campo de la producción jurídica colombiana cargas argumentativas propias de la escuela del activismo judicial, con gran similitud al nombrado caso de los guardias del Muro de Berlín fallado por el Tribunal Constitucional alemán. Finalmente, como lo expone Ferrajoli en su teoría jurídica, «toda decisión judicial tiene un gran impacto político», y en Colombia este no se hizo esperar, porque con las reacciones del poder ejecutivo al conocer la decisión judicial, se motivó el impulso del actual acto legislativo que pretende reformar la justicia penal militar.

A continuación se realizará un análisis minucioso de los fallos emitidos contra el paladín de la democracia, como coloquialmente las víctimas de los desaparecidos de la operación tricolor y rastrillo llaman al coronel Plazas Vega.

El 11 de junio de 2010, el Juzgado Tercero del Circuito Penal Especializado de Bogotá emitió condena contra el coronel (R) Luis Alfonso Plazas Vega, en el proceso adelantado en su contra por la desaparición forzada de 11 personas, que debido al material probatorio presentado por la Fiscalía y las victimas, se comprobó que salieron con vida del Palacio de Justicia el 7 de noviembre de 1985, trasladados a la casa del florero y desde entonces se desconoce cualquier noticia sobre su 
paradero. El coronel Plazas fue declarado culpable por la desaparición forzada agravada de dichas personas, y condenado a treinta años de prisión. La defensa del coronel Plazas Vega interpuso recurso de apelación y el Tribunal Superior de Distrito Judicial de Bogotá, en fallo emitido en enero de 2012, se pronunció de la siguiente manera, según los criterios presentados a continuación:

Desde una parte penal, al coronel Plazas le fue imputado el delito de desaparición forzada, ya que el material probatorio de la investigación efectivizó el nexo causal que se genera desde la comprobación, ratificación y aceptación de la salida con vida de personas que se encontraban en el interior del Palacio de Justicia y su posterior traslado por personal del Ejército al Museo Casa del Florero 20 de julio, el día 7 de noviembre de 1985, momento en que el Ejército había acabado los focos de resistencia subversiva en el interior del Palacio, y controlaba por completo sus instalaciones, personas sobre las cuales actualmente se desconoce su paradero, dicho delito fue imputado a título de autor mediato:

La autoría mediata hace referencia a la responsabilidad que cabe a un determinado sujeto, por la realización de ciertos actos punibles cometidos en un aparato organizado con relaciones jerárquicas de poder con carácter legal la mayoría de la veces, dicha figura se caracteriza por que la realización material del delito no es cometida por el autor mediato, pero si es materializada por medio de su voluntad directa es decir mediante la trasmisión de órdenes, a sujetos que se encuentran a este subordinados. (Roxin, 2006, p. 289)

Además, la imputación se hace a titulo agravado, puesto que la conducta se cometió por una persona que ejercía autoridad y jurisdicción, utilizando bienes del Estado y realizando acciones sobre el cuerpo de las víctimas para entorpecer su identificación. Para el Tribunal Superior de Distrito Judicial de Bogotá es clara la responsabilidad penal del coronel Plazas en la desaparición forzada agravada de dos de las once personas mencionadas antes, pues según el material probatorio, como vídeos, testimonios y grabaciones de interceptaciones de las trasmisiones oficiales realizadas por los medios de comunicación y radioaficionados que captaron la frecuencia del Ejército durante la operación tricolor (nombre que se dio a la operación para retomar el Palacio de Justicia), es idóneo establecer solamente la salida con vida del Palacio de Justicia de la militante del M-19, Irma Franco, y Carlos Augusto Rodríguez Vera, administrador de la cafetería del Palacio de Justicia, con base en los testimonios del soldado Yesid Cardona y las grabaciones de vídeo aportadas por el periodista Ramón Jimeno, en las cuales se identificó plenamente a estos dos últimos sujetos mientras salían con vida del Palacio de Justicia. Además, para el tribunal existe certeza de que el coronel Plazas emitió órdenes a sus subalternos, destinadas a consumar un ilícito, como la de clasificar a los supervivientes en el interior de la Casa del Florero, dando un trato especial a los que eran considerados especiales, 
trato que sobrepasó los límites legales, buscando encontrar posibles militantes del M-19 o auxiliadores de este que para la inteligencia militar facilitaron la toma del Palacio, o su célebre orden: ¡Cuelguen a esos «hijos de puta». Todo con aprobación y complacencia del general Jesús Arias Cabrales, superior directo del coronel Plazas en la Brigada XIII. Así lo demuestra el contenido de las radiocomunicaciones entre «Arkano y Paladín», seudónimos correspondientes al coronel Plazas y al general Arias, al escuchar en estas: «si está la manga, que no aparezca el chaleco, pero antes trabajen para que canten».

De las restantes nueve personas, los magistrados del Tribunal Superior de Distrito Judicial de Bogotá coinciden en que no hay material probatorio para demostrar su salida con vida del Palacio de Justicia y posterior desaparición. Por la desaparición forzada de Irma Franco y Carlos Augusto Rodríguez Vera, se encuentra culpable al coronel Plazas, ratificando la pena impuesta en primera instancia, la cual fue de treinta años de prisión; además se suman otras prestaciones que debe realizar el Ejército, como la prohibición de que cualquier unidad militar en el presente o en el futuro lleve el nombre del condenado: se ordena al Ejército pedir disculpas públicas al país y a las víctimas por los hechos atroces cometidos durante la retoma del Palacio de Justicia, construir un monumento en honor a la memoria de los desaparecidos y se compulsan copias a la Corte Penal Internacional solicitando se investigue la conducta de Belisario Betancourt presidente de la República para la época de los hechos.

Desde un enfoque constitucional la defensa del coronel Plazas aduce: «se está ante una tajante violación de principios constitucionales esenciales, concretamente argumenta que se está violando el principio de legalidad debido a que durante la fecha de comisión de los hechos, el delito de desaparición forzada no se encontraba tipificado por el Código Penal de 1980, sino el de secuestro agravado que de forma lógica significaría la prescripción del término para penalizar el ilícito. Ante esto, el fiscal responde que no se está violando el principio de legalidad debido al ius cogens o derecho internacional consuetudinario, el cual hace referencia a la conciencia internacional que da estatus axiológicos a derechos esenciales de todos los seres humanos y a su vez da el mismo carácter a conductas que menoscaben de forma grave o contraríen la praxis de dichos derechos catalogándolos como delitos. El derecho internacional consuetudinario fue legado al mundo por la sociedad romana mediante la figura del derecho de gentes, centrándose en posturas epicúreas que postularon los derechos universales de todos los seres humanos y la justicia como principio rector de todas las sociedades, acogido por la Organización de las Naciones Unidas luego de la Segunda Guerra Mundial, como medio de prevenir los crímenes de lesa humanidad, dictados como atentados a bienes jurídicos por la conciencia universal. Pues para la época de los hechos Colombia ya había ratificado la Declaración Universal de los Derechos Humanos, el Pacto de Derechos Civiles y Políticos, el 
Pacto de San José de Costa Rica, entre otros. Todos estos mencionan la desaparición forzada como delito de lesa humanidad, y con especial atención el Pacto de Derechos Civiles y Políticos dice que se entenderá como delito la desaparición forzada en un Estado que ratifique el tratado, así su ordenamiento interno no lo tipifique, ya que este es un delito de lesa humanidad sobre el cual se adoptan medidas especiales internacionales evitando su comisión; además dichos tratados pertenecen al bloque de constitucionalidad de forma activa, según como lo dispone el artículo 93 de la Constitución Nacional de la República de Colombia. Desde este punto de vista, la argumentación jurídica de la decisión judicial emitida se ubica dentro de la escuela del activismo judicial, pues el papel del juez va mucho más allá de la legalidad en la solución de casos difíciles buscando optimizar principios de justicia material, «para transmitir confianza a los coasociados en la administración jurisdiccional evitando así la solución de los conflictos por particulares no investidos de jurisdicción, efectivizando la democracia a partir de los principios del núcleo esencial de derechos fundamentales los cuales tienen vigencia por si mismos ubicándose por encima de cualquier orden legal» (Habermas, 2010, p. 103), desarrollando un contenido similar a los casos reconocidos globalmente, como el de los guardias del Muro de Berlín, fallado por el Tribunal Constitucional alemán utilizando el controvertido principio de Radbruch (cuando el derecho es extremadamente injusto deja de ser derecho); el caso de las casas del barrio Alto en Perú; el caso de la operación cóndor, y demás propios de las dictaduras militares del siglo XX, vividas en países suramericanos como Argentina y Uruguay. La característica de estos casos fallados durante la última década es que se efectiviza la evolución jurídica, que se aleja de preposiciones axiológicas rígidas, como ámbito de justicia formal, y toma como centro de gravedad la justicia material como instrumento racional para el esencial funcionamiento de la sociedad, «la efectivizarían de la justicia material, es la condición básica que permitirá la construcción de la democracia y apertura de caminos de paz, en sociedades cuyo principio rector fue la irracionalidad de la violencia auspiciada internamente por la legalidad» (Atienza, 2009, p. 56).

El general Jesús Armando Arias Cabrales fue condenando a treinta años de prisión por la comisión de los delitos de desaparición forzada de las 11 personas que salieron con vida del Palacio de Justicia, en fallo de primera instancia. Después del conocimiento público de los fallos en mención, el poder ejecutivo impulsa un acto legislativo, que busca reformar la jurisdicción penal militar blindando jurídicamente a los militares, evitando que se repitan condenas como las del coronel Plazas y el general Arias y así estimular la repetición de operaciones tricolor, las cuales no tendrán limite en su accionar cuando de defender el orden y la institucionalidad del Estado se trate.

El caso de los desaparecidos durante la retoma del Palacio de Justicia, es la prueba material del triunfo de la arbitrariedad y el poder sobre el derecho, que contraría la 
esencia básica de las democracias, siendo la justicia material y la verdad los caminos de reconciliación entre el país político y el país nacional, tratando de configurar la lógica de la verdad, la ética de la libertad y la estética de la vida como principios centro de gravedad de la democracia.

Además hay que agregar que después de la retoma del Palacio de Justicia se creó una comisión de la verdad liderada por el procurador general de la nación de la época, la cual tenía como fin esclarecer los hechos de los días 6 y 7 de noviembre. Esta comisión llegó a la conclusión que Iván Marino Ospina acordó tomarse el Palacio de Justicia con Pablo Escobar, bajo la financiación de «los extraditables», para destruir los expedientes en su contra existentes en el archivo del Palacio de Justicia. Se condecoró al presidente Betancourt y a todos los mandos militares que participaron en la operación tricolor, con la Cruz de Boyacá, dándoles el título de héroes y salvadores de la democracia. Se dijo que algunos de los desaparecidos eran militantes del M-19, los cuales, luego de salir con vida del Palacio de Justicia regresaron a las montañas para unirse a la insurgencia, y los demás fueron asesinados por el M-19 durante la toma. Debido al incendio de la biblioteca, sus cuerpos se calcinaron, razón por la cual no aparecieron. Resultado bastante disímil al mostrado por la Fiscalía en las investigaciones contra el coronel Plazas y el general Arias, pues allí se comprobó que no hubo ningún acuerdo entre los «extraditables» y el M19, ya que la prueba reina que ratificaba dicha premisa era el testimonio de John Jairo Velásquez Vásquez (Popeye) guardaespaldas de Pablo Escobar, el cual aducía haber presenciado la reunión entre Iván Marino Ospina y Escobar, pero para la fecha en que dijo haberse realizado dicha reunión, Iván Marino Ospina llevaba cuatro meses de haber sido asesinado por agentes de la inteligencia de la Policía, lo cual desvirtuó su testimonio y desechó dicha hipótesis. Se comprobó que el fuego en el Palacio de Justicia fue ocasionado por el impacto de munición incendiaria disparada por un tanque o desde un rocket por el Ejército, debido a que el disparo se hizo desde afuera del Palacio, hecho que hace tomar fuerza a la hipótesis según la cual el Ejército aprovechó la toma del Palacio de Justicia para quemar los expedientes de investigaciones que la Corte Suprema de Justicia había abierto contra altos mandos militares por violación de derechos humanos, nexos con el MAS (muerte a secuestradores) y el narcotráfico. Terminaron entonces condenados el coronel Plazas y el general Arias por la desaparición de personas rescatadas con vida del Palacio de Justicia.

Se inició así una persecución contra la rama judicial, violando principios rectores del Estado moderno, como la división e independencia de poderes, asentando la mal llamada oposición en el interior del poder estatal, ya que en un país y una democracia como la de Colombia, ejercer sus labores objetivamente significa un factor de oposición, cuando debería ser un factor de contención, límite y equilibrio de las facultades estatales como medio de armonizar la democracia. Todo esto se 
ha dado bajo la errada concepción del enemigo interno, que gobierno tras gobierno legitima el uso de la violencia como control estatal, al estilo de la caza de brujas en la Inquisición. En el brumoso y oscuro panorama nacional se vislumbra la justicia material como una luz que busca cimentar los valores de reparación y verdad como único camino sensato de construcción de la democracia y vía para la paz en Colombia, siendo esta luz la independencia y la objetividad que intentan rescatar la dignidad y el respeto por las instituciones del país.

La toma del Palacio de Justicia deriva de la inequitativa distribución de la riqueza social en Colombia, la cual genera realidades de facto violentas, traducidas en conflictos entre los poseedores y los desposeídos que abogan por grandes cambios en las estructuras socioeconómicas que permitan su inclusión y participación en la vida política del país. A su vez, la concepción guerrerista de solucionar el conflicto armado nacional mediante la derrota militar de la insurgencia, lleva a que se trunque el camino de la paz y se produzcan resultados nefastos como los del 6 y 7 de noviembre de 1985, luego de la retoma, días en los cuales la arbitrariedad irracional del poder ilimitado primó sobre la legalidad, el orden, la democracia y la Vida.

Dedicado a la memoria de los abogados de profesión pero TRANSFORMADORES SOCIALES de vocación, que perdieron la vida los días 6 y 7 de noviembre de 1985 en el Palacio de Justicia (especialmente a Andrés Almarales, Irma Franco y Luis Otero).

\section{Referencias}

Atienza, M. (2009). Derecho y argumentación jurídica. Bogotá: Universidad Externado de Colombia.

Bateman, J. (1982). Conferencia VIII general del M-19, montañas del Cauca, Colombia.

Habermas, J. (2010). Facticidad y validez. Madrid: Esquilo.

Petro, G. (2007). Dos miradas acerca de la toma y retoma del Palacio de Justica. Bogotá: Escritores.

Roxin, C. (2006). Derecho penal, parte general, participación típica. Buenos Aires: Universidad de Buenos Aires.

Vargas, A. (2006). Estudios sobre el conflicto armado en Colombia. Bogotá: Facultad de Sociología, Universidad Nacional de Colombia.

Villamizar, D. (2007). Biografía de un revolucionario. Bogotá: Intermedio. 